\title{
The strategising roles of public sector middle managers
}

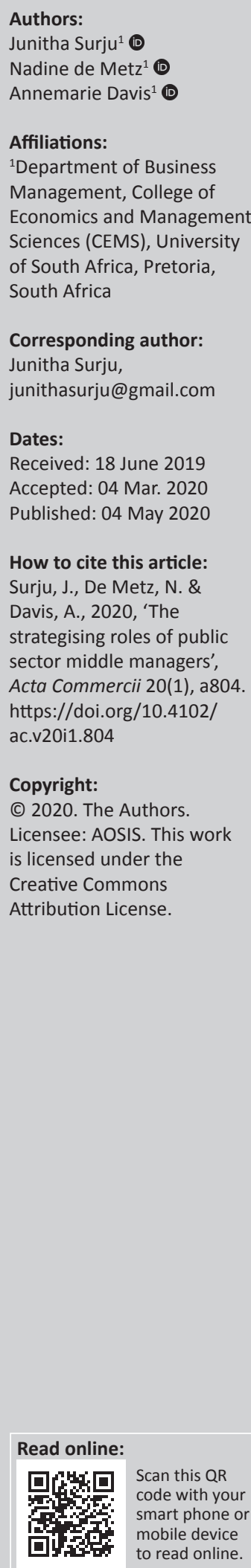

Orientation: Whilst research on middle managers has increased considerably, research on the role of middle managers in the public sector context remains a rich context for exploring strategising.

Research purpose: The purpose of this research was to explore the strategising roles of middle managers in the public sector through the strategy-as-practice perspective.

Motivation for the study: The article responds to calls for research using the strategy-aspractice perspective to explore the role of middle managers in the public sector.

Research design, approach and method: The research adopted a qualitative exploratory case study design. The data was gathered using semi-structured interviews conducted with 14 middle managers at a selected government department.

Main findings: The research findings confirm that the strategising roles of middle managers in the public sector comprise of three key roles: sense-making and sense-giving role, the implementation role and monitoring and evaluation role. Within the public sector context, strategies are mostly deliberate and driven from national plans. When middle managers 'receive' these strategies, they make sense of it and then communicate the strategy to their subordinates through their own interpretations involving both horizontal and vertical communication channels.

Practical/managerial implications: The findings confirm benefits for involving middle managers in the crafting of high-level strategy in government departments which may lead to them owning the strategy and implementation thereof.

Contribution/value-add: The research adds value by confirming the middle managers' strategising roles within the chosen government department and identifying how changes to their roles can enhance strategising.

Keywords: public sector; government department; strategy-as-practice; strategising roles; middle manager.

\section{Introduction}

The contemporary approach to management holds that middle managers are influential strategists, whereas the traditional approach indicates that strategy is the domain of top management. In recognising the importance of middle managers, this research set out to explore the strategising roles of middle managers in a public sector setting. Managerialism in the public sector is one of the key trends in public sector reform (Mayne \& Zapico-Goni 2017). However, it was not only the rise of managerialism and the wider acknowledgement of the middle manager who informed this research. As practising managers and academics, we recognise the importance of the public sector that is responsible for the delivery of essential services to improve the lives of the citizens of a country.

The public sector concentrates on the provision of education, housing and water affairs, amongst various other basic services (Veldman \& Szabo 2015:10). The management processes followed in the delivery of essential services are important, and the understanding of these processes and practices cannot be ignored. Over the years, the public sector has drawn on business principles applied in the private sector to deliver on their directives.

Generally, both the public sector and the private sector apply similar strategic elements, such as strategy, strategic intent, purpose drive and the focus on encouraging staff to achieve the strategy (Alford \& Greve 2017:4). 
Although there are differences between public and private sector management and organisation, the failure rate of strategy implementation in both sectors still remains constant and troubling. Literature confirms that as many as $90 \%$ of the strategies formulated fail at the implementation stage (Candido \& Santos 2015:241-244). Given the body of knowledge that confirms the challenge of strategy implementation, it is important to include public sector officials in strategy research. Despite this apparent interest from the public sector, limited research has been published on the strategising practices of middle managers in a government department, especially within the South African context (Jooste \& Fourie 2009; Van Niekerk \& May 2012).

Because of the limited research on strategy in government, the main objective of this research was to determine the strategising practices and the roles adopted by middle managers within a selected government department.

A lack of understanding the lived experiences of middle managers in the public sector department may hinder effective strategy implementation which ultimately leads to poor service delivery. Furthermore, exploring the practices of middle managers in the public sector may not only acknowledge their contributions but also affirm their strategic roles. As such, we believe that an understanding of the strategising practices and roles of middle managers in the public sector may lead to changes in practices that could ultimately contribute to efficiencies in strategy implementation and the achievement of national development plans (NDPs).

We approached one department within the unique South African public sector context, from a practice perspective, to research how middle managers strategise. Essentially, we wanted to gather deep data that tell the story of middle manager's strategising roles, and the strategy-as-practice perspective enabled us to do so.

Reporting on research using the strategy-as-practice perspective within this journal is not new (Bornman 2017; Govender \& Pretorius 2015; Pretorius 2014; Stander \& Pretorius 2016). The strategy-as-practice perspective allowed us to study the strategising roles of the middle manager, emphasising the doing of strategy by studying the microactivities and then linking them to the macro-level activities of the organisation (Lê, Seidl \& Suddaby 2013:330). The elements of strategy-as-practice involve the practitioners (those who do the work of strategy), practices (the social, symbolic and material tools through which strategy work is performed) and praxis (the flow of activity in which strategy is accomplished) to understand the strategising roles of the middle manager (Salih \& Doll 2013:33). In addition, we support the view of Samra-Fredericks (2003:142) that strategising should be studied as a lived experience rather than as a recorded experience. The use of the elements of practitioner, praxis and practices offered us the opportunity to explore how the middle managers' actions shape the strategy within the specific department and enabled us to identify their strategising roles.

The literature review is structured as follows: firstly, a brief overview of the public sector in South Africa is provided. The article then discusses the rise of the middle management perspective and outlines the various roles middle managers are typically responsible for. The literature review concludes with the positioning of the middle manager within the chosen government department.

\section{The public sector in South Africa}

While recognising the size and scope of the South African public sector, we deliberately chose one department as a case study. For the purposes of this research, we selected a government department tasked with education.

In South Africa, about $68 \%$ of the budget goes to fund the social cluster priorities to provide citizens better access to opportunities and to live with dignity (National Treasury 2019:vii). Education is widely recognised as the top priority of government and it accounts for $24.1 \%$ of the expenditure in the South African economy (National Treasury 2019:54). The decision to focus only on one department was also informed by our desire to gather deep data in order to tell the story of the middle managers' strategising roles. Examining strategy as a lived experience assists with understanding how the strategy evolves over time and space (Samra-Fredericks 2003:169) and informs the body of knowledge on strategy implementation and control. At the time of the study, in the South African government context, the primary mandate was to improve the quality of education and training and to increase access (DPME 2014). To achieve this mandate, the government's priorities for education include early childhood development, schooling, further education and training, as well as higher education (NPC 2013). This research was conducted between the 8th and 10th months of the 2016-2017 financial year when the elected government was mid-way through the electoral cycle of 2014-2019.

As can be expected, strategies within the public sector are mostly deliberate and are developed from the goals set out in the NDP. The NDP sets out the priorities to be achieved up until 2030 (NPC 2013). After the adoption of the NDP, the 2014-2019 Medium Term Strategic Framework (MTSF) was developed and implemented to govern the national priorities for the period during which the study was undertaken (The Presidency 2014:5). The MTSF sets out the plan, which includes the priorities linked to the NDP that have to be implemented in the electoral cycle (DPME 2014:4). Government, in turn, develops strategies towards achieving its goals that are implemented by public sector employees.

All spheres of government are mandated to ensure policy coherence, alignment and coordination across government 
plans, as well as alignment with the budgeting processes (The Presidency 2014:5). One of the key planning documents includes a 5-year strategic plan that sets out the policy priorities, programmes and project plans of the departments for 5 years, as approved by its executive authority, within the scope of available resources (National Treasury 2010:6). The compilation of the 5-year strategic plan leads to the crafting of the Annual Performance Plan (APP) which narrates what is to be performed in a given year by a government department (National Treasury 2010:7). The APP includes indicators and targets for budget programmes and sub-programmes. All government departments, whether national or provincial, have an APP (National Treasury 2010).

Within each government department, the APP is translated from the strategic plan, while recognising the central control and need for compliance (Andrews et al. 2011:646). It is assumed that in a government context, there can be no uncertainty regarding what is required before any action is taken, as the intended actions link to the intended strategy (Mintzberg \& Waters 1985:258). The strategic plan is processdriven, involves action and is linked to time frames with specific outcomes to be achieved (Amason 2011:9; Güney \& Taylor 2009; Sloan 2014:10; Thompson \& Martin 2010:9).

While the government strategy is deliberate, elements of emergent strategies are visible. Emergent strategy is viewed as the use of that which works by taking a single action at a time in the quest for a viable pattern of stability (Mintzberg \& Waters 1985:271). This translates to an unintended order for the managers and organisations (Mintzberg \& Waters 1985:271). For example, when barriers arise, the middle manager can narrate what actions can be taken to overcome it, and this is seen as an emergent strategy (Horst \& JärventieThesleff 2016:15-16).

\section{Middle management perspective}

Traditional approaches in management and strategy indicate that strategy is the domain of top managers (Vaara \& Whittington 2012:308). However, the role allocation of these fundamental activities has led to many debates with various conflicting views being expressed. Literature still considers, to a large extent, strategy as a top-down process of formulation separated from implementation, predisposing a focus upon top managers, their demographics and their decision-making processes (Andrews et al. 2011:646; Mintzberg \& Waters 1985:258; Sting \& Loch 2016:1177-1193). Wooldridge and Floyd (1990) are considered to be some of the first scholars to warn against looking at middle managers only from an operational viewpoint. According to them, when top management looks at middle managers from only an operational viewpoint, they fail to make distinctions about the variety of contributions made by middle managers and, in particular, overlook the possibility that middle managers play strategic roles. The contemporary model of the middle manager is one that has a more strategic focus and is more concerned with making strategic decisions impacting the strategic direction of the organisation, than the traditional model of the middle manager. The traditional model of the middle manager is limited in its view of middle managers as mostly operational managers are tasked with implementation activities.

In line with the strategy-as-practice perspective, strategists consist of a much wider group of actors - including managers at multiple levels of the organisation, as well as influential external actors, such as regulators and consultants (Jarzabkowski \& Whittington 2008:282). Increasingly, strategy-as-practice studies indicate the importance of middle managers and lower level employees as strategic actors (Jansen van Rensburg, Davis \& Venter 2014; Mantere 2008:305-307; Peris-Bonet, Canet-Giner \& Lavarda 2010:361; Wooldridge \& Floyd 1990:232). In a recent study by Jones and Hooper (2017:492), middle managers in the public sector were identified as key officials in implementing strategy. The same was found in the private sector, as the middle manager assists in the implementation of the new macro-designs of an organisation by building micro-level structures (Livijn 2019:19). Lystbæk, Holmgren and Friis (2017:40) indicate that strategy is extremely important for service delivery and there is now an emphasis on strategising within the public sector.

By identifying middle managers as strategists, we were able to explore their lived experiences and practices and contribute to the body of knowledge on middle managers in the public sector. Our study bridges the gap that still exists as most of the current studies on the middle manager do not explicitly focus on their strategising role within the public sector in a developing country (Hansell 2018; Jones \& Hooper 2017; Joshi \& Jha 2017; Lystbæk et al. 2017; Livijn 2019; Olsson, Aronsson \& Sandberg 2017).

\section{Roles of the middle manager}

Literature indicates that the roles of middle managers are diverse and varied across different contexts. The middle managers are seen as linking pins that have upward, downward and lateral influence (Nonaka 1988:15; Rouleau, Balogun \& Floyd 2015:599; Sting \& Loch 2016:1177-1193). They play a crucial role in translating top management's strategic objectives through the generation of new ideas and the communication and facilitation of the strategy (O'Shannassy 2009:199; Peris-Bonet et al. 2010:361; Salih \& Doll 2013:36).

Therefore, one of the key roles identified and widely recognised is the role of middle managers as implementers of strategy (Mantere 2008:305-307). Aside from this role, they fulfil the roles of motivators and coaches, as they are in strong positions to recommend, initiate and assess alternative courses of action when the need arises (Mantere 2008:305-307; Peris-Bonet et al. 2010:361; Wooldridge \& Floyd 1990:232-238). 
Middle managers play a fundamental leadership role as they are expected to monitor activities, and require the ability to make sense of the activities needed to successfully implement the strategy (Jooste \& Fourie 2009:66; Salih \& Doll 2013:33). The sense-making and sense-giving roles of middle managers are crucial in the successful interpretation and articulation of the strategy to their staff. Sense-making allows the middle managers to assess the viability of proposed strategies (Salih \& Doll 2013:33). The middle managers' sense-making also depends on their use of knowledge of a situation and their ability to articulate and convince others to follow the decisions made by top managers (Balogun \& Rouleau 2011:972). Hence, they inspire learning and are seen as visionaries (Döös, Johansson \& Wilhelmson 2015:417). Sense-giving is closely linked to sense-making, and occurs when the middle managers are able to guide officials who work with them to reject or change their beliefs in favour of a new set of beliefs (Cornelissen \& Schildt 2015:358).

Furthermore, in managing their staff, the middle manager has to implement corrective measures when the behaviour of lower level staff members falls below expectations (Salih \& Doll 2013:33). Hence, the middle managers monitor the progress of their employees' work against organisational objectives and provide feedback to such employees, as the strategic intentions, employee actions and activities need to be aligned (Gilbert \& Sutherland 2013:5; Salih \& Doll 2013:35). In addition, middle managers provide support to improve the work of the officials working with them (Jansen van Rensburg et al. 2014:170).

Within the African context, middle managers have been viewed as adopting various strategic roles including champions, synthesisers of information, facilitators and implementers (Jansen van Rensburg et al. 2014:172; Katoma \& Ungerer 2011:38-40; Mantere 2008:305-307). In undertaking these roles, the middle managers have to generate ideas, develop policies and support strategic initiatives that differ from their current conception of strategy. It is evident that middle managers adopt a variety of complex roles that they are expected to perform on a daily basis.

\section{Positioning the middle manager within the focal organisation}

Within the chosen government department, the middle management staff members occupy posts that involve highly skilled supervision. Furthermore, the job title 'middle manager' is explicitly found within the organisational structure of the chosen government department. While we set out to specifically explore the strategising roles of the middle managers, we first set out to consider the middle manager in terms of the operational function and hierarchical placement. Therefore, an official occupying a middle management post in this context is defined as a manager who occupies a position within four levels below the head of the department, and one or more levels above the staff that they supervise. In addition, we recognised the position that middle management occupies as a buffer between the top managers and first-line managers (Marin 2012:118). For this research, we chose Deputy Directors (DDs) and Chief Education Specialists (CESs) as the target population for the study. The DDs and CESs who participated in the research are appointed on the post levels 11 and 12.

\section{Research methods and design}

This exploratory study was undertaken during the 2016 and 2017 financial years within one government department tasked with education. We deemed the constructivistinterpretivist paradigm as appropriate as we conducted an indepth analysis of the day-to-day workplace practices of middle managers during strategising. The overarching research design was a single case study that led to the production of rich and detailed data (Ridder, Hoon \& McCandless 2015:159-163). We set out to study the participating middle managers in the real world as they pursue their lives within their work environment (Yin 2011:7).

The staff strength of the chosen government department was around 750 at the time of the research. The middle managers comprised the greatest section of the staff component, with 356 employees in these supervisory posts on levels 9-12. The employees in middle management are appointed against the post of DD, CES, assistant director and deputy education specialist in the selected government department. The sampling strategy used was a non-probability strategy, which allowed us to deliberately choose participants from a carefully selected sample. We identified 20 possible participants who met the following criteria: they should have professional backgrounds or differing roles, cover both men and women, cover all races and they should be permanent appointees in the post for at least 1 year. Overall, 14 middle managers participated in this research. The participating middle managers had a range of different roles and worked in curriculum, budgeting, internal auditing, human resources, societal issues and branch coordination. At the time of the study, all participants had been in their posts for more than 3 years.

\section{Research instrument}

We selected interviews as the data gathering instrument for this case study, as it enabled us to gather in-depth data focusing on human affairs and behavioural events (Gillham 2008:62; Yin 2009:107, 109). We also decided to use a semistructured interview guide as it offers the ability to provide rich data. Our interview guide provided for some general questions to build rapport, followed by the questions that aimed to explore the roles and activities of the middle managers. The questions generally started at the organisational level, and then focused on the directorate level, before moving onto middle managers themselves and 
their experiences. This research was conducted under the research ethics clearance provided by the Department of Business Management Research Ethics Committee at the University of South Africa and with the permission of the chosen government department. The research reported in this article forms part of a broader study.

We utilised components relating to trustworthiness of the research which included transferability, dependability, credibility and confirmability (Flick 2014:576). The participating middle managers had received a clear explanation of what the researcher expected from them so that they could make an informed choice regarding whether to take part in the research or not (Bertram \& Christiansen 2014:65). The middle managers then signed an informed consent form prior to the start of each interview. In addition, each interview was recorded, and the transcriptions of the interviews were performed by an independent transcriber. The transcriber signed a confidentiality agreement prior to the start of the transcription of the interviews.

We gathered $313 \mathrm{~min}$ of data through the interviews. Once transcribed, the data amounted to 38229 words across 106 pages. The transcribed data were kept in a safe place and access was limited to only the researchers. All the participating middle managers were assigned a pseudonym and the files were kept under an alias file name.

\section{Data analysis}

We employed thematic analysis to identify themes and patterns within the data. Thematic analysis enabled us to check themes across the entire data set. We were guided by Saldaña's (2009) framework that covered preliminary jottings, pre-coding, first-cycle coding of the data, refinement of first-level coding and second cycle coding. The first cycle of coding took place in April 2017, and we used Atlas.ti to coordinate and manage the process. With the first cycle of coding, we identified 11 themes. During the second cycle of coding, the themes were reduced to 9, with categories and sub-categories. We also engaged with an independent co-coder to enhance the trustworthiness of our analysis.

\section{Ethical consideration}

The research was approved by the University of South Africa's (Unisa) Review and Ethics Board. The study was approved by the Department of Business Management Research Ethics Review Committee at Unisa on 12 September 2016 (Ethical Clearance number: 2016_CEMS_BM_51).

\section{Findings}

This section positions the strategising work of the middle manager within the government department context. It was found that there were many similarities between the roles that the public sector managers adopted and the roles adopted by private sector middle managers as described in the literature. These similarities will be discussed in this section.
In terms of the crafting of the strategy in this unique context, the participants provided feedback that the strategies were predominantly deliberate and received from top management level. The strategies are informed by the NDP and MTSF and translated into the departmental 5-year strategic plan and APP.

A number of key activities and roles were identified during our first cycle of coding. Through a second cycle of coding and our interpretation of the findings, we classified the roles and activities of the participating middle managers within the selected government department into three key roles. These roles were categorised according to (1) sense-making and sense-giving roles, (2) the implementation role and (3) the monitoring and evaluation role. We expected confirmation of the implementation role, given the deliberate strategies, central control and compliance-driven context of the public sector. Despite this, we found that the middle managers not only operationalise the deliberate strategies, but our findings indicated that they also devise new strategies (emergent) as it might become necessary while performing their strategising roles. This was an important finding and showed that despite the participating middle managers operating in a restrictive environment, they were in a position to develop emergent strategies that aided the implementation of the deliberate strategy.

Figure 1 presents a diagrammatical depiction of our findings and serves as the framework to discuss the findings.

Figure 1 positions the strategising work of the middle manager within the government department context. Figure 1 illustrates that, typically, there are deliberate strategies communicated from top management level. These strategies are informed by the NDP and the MTSF, key documents established by the presidency. The middle managers viewed these documents as long-range planning documents covering a time span of 1, 5 and 30 years. The NDP and MTSF depict the high-level priorities of each sector of government. The NDP and the MTSF influence the individual departments' 5-year strategic plan and APP.

The following section offers a discussion of the findings regarding the three key roles that were identified.

\section{The sense-making and sense-giving role}

It became clear from the results that the sense-making and sense-giving roles of middle managers were crucial in aligning strategies vertically and horizontally between top management, lower management and officials from other departments.

Within the centralised planning context of the public sector, our findings confirmed that when middle managers 'receive' the strategy, they make sense of it and then give sense to their subordinates. According to the participating middle 


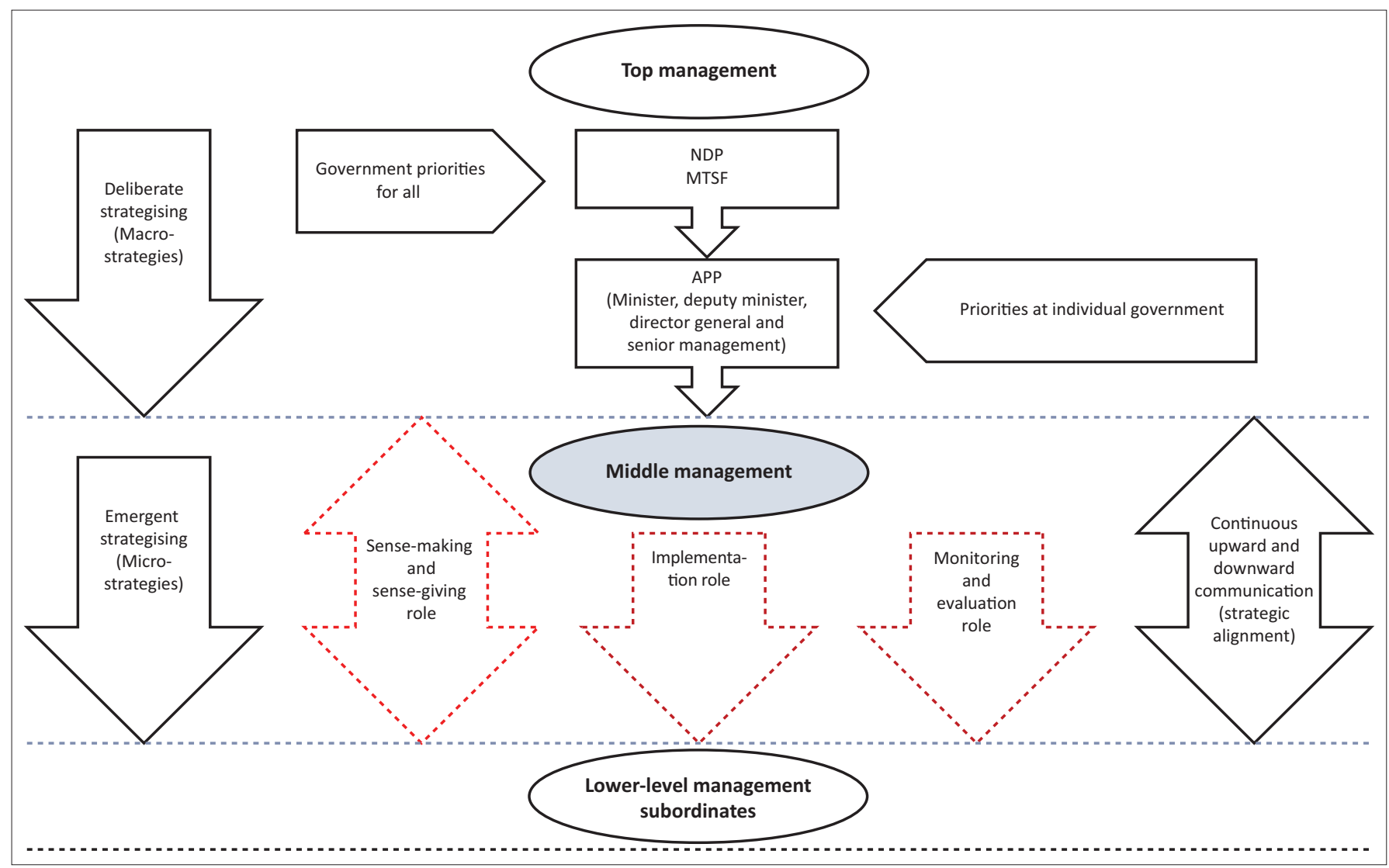

NDP, National Development Plan; MTSF, Medium Term Strategic Framework; APP, Annual Performance Plan.

FIGURE 1: Middle Managers' perspective on strategising within the government department over the 2014-2019 electoral cycle.

managers, they make sense of the strategies by developing their own frameworks based on their own knowledge and experience to convince others to follow them in the implementation of strategy. Our findings thus confirm that the middle managers play a crucial link between top management and lower level staff.

In making sense of the strategies, the middle managers needed to assess the complexity of the deliberate strategies in order to operationalise them. This meant that they were involved in sense-giving as they needed to interpret the department's strategy for themselves so that they could communicate them to their subordinates. The middle managers had to assess the practicality of implementing the strategy even if it was complex. The middle managers can then communicate their assessment of the strategy to their senior managers and how the strategy can be implemented. Stemming from this, interpreting and translating the strategy effectively to lower level management was thus an important task that middle managers were responsible for in unpacking the strategy and its desired outcomes.

One middle manager explained how she 'looks at the strategy, breaks it down into activities and performance indicators and then shares that with her staff'. It also became apparent that middle managers used their knowledge of a situation and their articulation thereof to convince others to follow the decisions made by top managers (Balogun \& Rouleau 2011:972). The middle managers therefore drew on their sense-making and lived experiences in translating the strategy for the lower level staff who work with them at directorate level.

We found evidence to support Orlikowski (2015:34) and Samra-Fredericks (2003:146) that the lived experiences of the middle managers assisted them with attaining the linkages between the micro- and the macro-strategies which make up organisational life. Furthermore, the key findings showed the link between the micro- and macrostrategies of the government department, as explained in the excerpt below:

'Sometimes policy dictates to you that you should do A, B, C and $\mathrm{D}$. And then one sometimes gets a directive from the director to say this is what is supposed to be done but you give advice as an expert in that area to say this is how things should be done'. (Middle manager, 15 years' experience, female)

The results highlighted the importance of informal employee relationships as the middle managers often had to make use of informal networks and communication to expand on their sense-making.

One of the middle managers with 20 years of experience stated that he would contact staff in the other departments to assist him to resolve the queries that he had to solve. 
Furthermore, the informal networks were confirmed in the excerpt below:

'One needs collaboration between the different directorates. One cannot work in silos and be able to achieve the objectives that it needs ... for example, in terms of digital content, I need to work with the ... directorate, because the books that they produce in print I turn them into digital'. (Middle manager, 12 years' experience, male)

There were three strategy tools that played a key role in supporting the sense-making and sense-giving practices of middle managers. The three tools included meetings, workshops and plenary sessions and provided an opportunity for the middle managers to liaise with the staff face to face. The findings indicated that these tools serve as boundary objects because the tools promote communication and the sharing of ideas by different strategy actors, which align to the views of Spee and Jarzabkowski (2009:228). The following quote from a participant explains the importance of meetings:

'In meetings, that's where you get to see the reality of what is happening because sometimes people write and you misinterpret what they have written but, when we have meetings, then you are clear of whether this thing is achieved or not achieved or if we are moving behind or whatever'. (Middle manager, 9 years' experience, female)

Our findings confirmed the views of Carpenter and Jiang (2013:13) that middle managers play an essential role in knowledge transfer between officials with whom they regularly interact.

\section{Implementation role}

Once the middle managers have used their sense-making and sense-giving role to interpret the department's strategy for themselves and for officials who reported to them, the next role as expected, the most prominent role was that of implementation. The middle managers were primarily involved in implementing strategy and they fulfilled this role of implementing the strategy through translating the APP into directorate-level operational plans. They achieved this by facilitating the breakdown of the strategy into achievable outcomes at directorate level and at levels below their level (Vaara \& Whittington 2012:308). One middle manager described the middle manager's involvement in the implementation role as follows:

\begin{abstract}
'As a middle manager, I've been called upon to input into higher level decision-making and, for instance, in our department, if I can just use an example of the National Development Plan, we, as middle managers, have been requested to engage with the National Development Plan and rephrase our key performance deliverables, which then get translated into our directorate's annual strategic plan, as well as our own work plans'. (Middle manager, 20 years' experience, female)
\end{abstract}

In implementing the strategic plan, the middle managers annually review the APP of the department to gauge whether the work of the directorate is aligned to the MTSF. The APP, in turn, guides the operational plan of the directorate. The directorate has its own goals and reports on targets and indicators that are related to the goals. It is a significant role of the middle managers because it confirms that they are involved in aligning to the high-level plan of government.

The middle managers explained the key responsibilities associated with their implementation role:

'Within my work plan ... overall, I am responsible to ensure that our sub-directorate functions well, effectively, but, within the sub-directorate, we have specific programmes and in these programmes we have allocated ourselves responsibilities'. (Middle manager, 10 years' experience, female)

Furthermore, in their implementation role, some of the participants stated that they also provided training and served as project managers. The project management tasks are described by one participating middle manager as follows:

'So, based on those strategic objectives ... you have to indicate
what is it that you are going to do, how, and indicate the plan with
a date and the responsible person and, also indicate the stakeholders
that will be there so that you can be in a position to achieve ... what
you want to achieve. So we usually make inputs ... at the level
where we are, we make inputs towards the overall strategy of the
department'. (Middle manager, 12 years' experience, female)

Middle managers as part of their implementation role also supervised the staff and promoted teamwork. A middle manager described the teamwork between him and his subordinates as follows:

'So what we will do, after we have developed the operational plan, then it will go into our work plans. What is my role in making sure that this is achieved as a supervisor? My role then is to supervise my two colleagues, but before I supervise them, we will plan together. We will plan together and say do you see your role here? Do you accept this role?' (Middle manager, 10 years' experience, female)

Middle managers strive to attain the directorate's objectives by aligning with the planning documents of government this is seen as 'driving compliance' as found by Jansen van Rensburg et al. (2014). Similar to the findings of Mantere (2008:305-307), Peris-Bonet et al. (2010:361) and Wooldridge and Floyd (1990:232), the participant's role as the implementer of strategy was vital in the context of the study.

\section{Monitoring and evaluating role}

A crucial role of any organisation is to track a strategy, once it is implemented, in order to gauge whether the strategy has been achieved or not (Rouleau et al. 2015:599-600). Thus, it was not surprising that the participants stressed the crucial monitoring and evaluating role of the middle managers within the department once the strategy was implemented. The monitoring and evaluation role was multi-directional as middle managers had to continuously communicate upwards (through reporting) and downwards (through meetings and supportive sessions with subordinates). One participating middle manager specifically stated that once a common understanding of the strategy is established, and 
implementation is commenced, 'it's now for me to monitor and support. That's my role'.

An important task highlighted by the middle managers was to compile progress reports on their work plans on a quarterly basis. One of the participants stated that in order to carry out her monitoring and evaluating role, she would provide feedback on reports sent to her by identifying shortcomings and gaps and alerting the officials who generated the reports so that the shortcomings could be addressed. The participant explained this in the following excerpt:

'So my role, specifically, would be not only to deal with them in terms of reporting ... planning and reporting but also to alert them if they go astray and also, again, to align our strategy with the risk management because they cannot go separate ways. They always have to marry each other'. (Middle manager, 9 years' experience, female)

The monitoring and evaluating role was also important in terms of analysing whether the resources that were allocated were sufficient. Checking on the budget and the spending trends assisted some middle managers to support and monitor the strategy of the focal government department.

In terms of how the monitoring and evaluation takes place, these middle managers explained:

'... We'll develop templates to guide the Departments on what they need to report based on the strategy. Like, for instance, we will collect information on the plans, we will analyse that information, we will make reports which we report against the strategic objectives of the department on a quarterly basis, and then we will also indicate, if ever we are reaching our target, we are achieving our target or not'. (Middle manager, 15 years' experience, female)

'So I make sure that at least we have one meeting every month with my team to ... we write down the priorities for the month and we work on them, we review whether they've been achieved

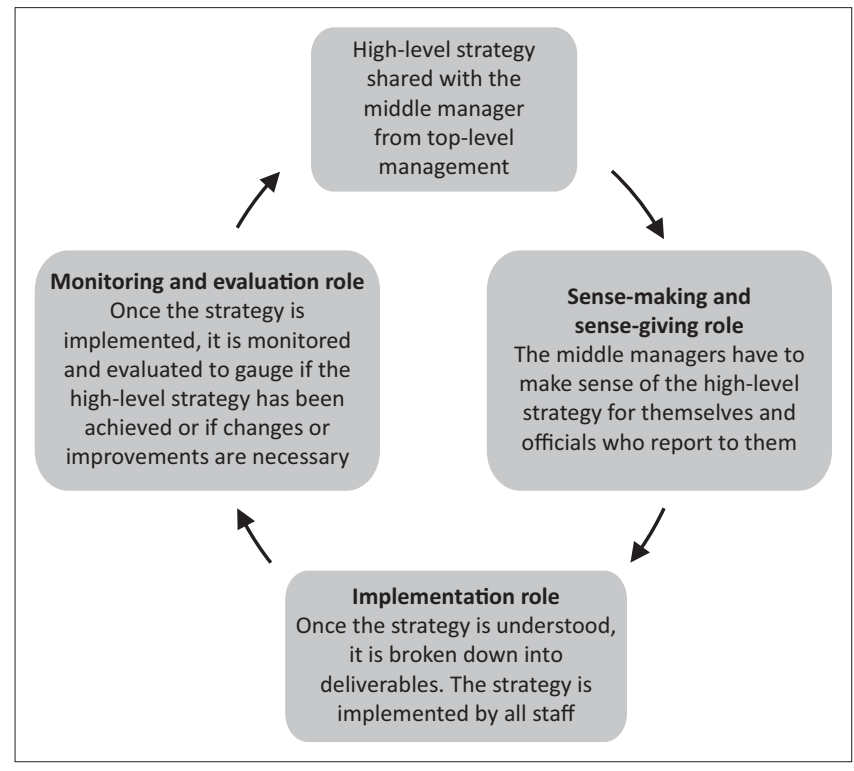

FIGURE 2: Interlinking of the strategising roles of the middle manager. or not, and we can track progress. So that really works for me'. (Middle manager, 10 years' experience, female)

The findings indicated that the monitoring and evaluation role largely involved the analysis, reporting and dissemination of data. An important task of some of the participants was to analyse large-scale data and interpret the data to communicate the information to the education department.

When dealing with challenges, the results showed that the middle managers crafted micro-level emergent strategies to overcome these challenges. This highlights the notion of bottom-up decision-making within the department (Cardoso \& Lavarda 2011:3). The emergent strategies were evident through the flow of activities and actions that the middle managers prioritised in order to achieve the deliberate strategy. An important task of the middle managers was to advise the lower level employees regarding what work needs to be reprioritised, to ensure that the desired results were achieved. Figure 1 shows that there is continuous alignment of the strategy through upward and downward communication. So, if a problem arises with regard to the strategy, the middle managers can communicate this to top management within the government department.

Within a supervisory role, middle managers were responsible for monitoring the activities and progress of the lower level staff. The middle managers therefore had to ensure that the government department, employee actions and activities were aligned (Salih \& Doll 2013:35). In facilitating this role, the middle managers drew up work plans for their staff members, which were monitored on a quarterly basis. They also monitored the performance of their staff members and provided support to or had to take corrective action when the performance was below the required standard.

Figure 2 builds on the framework of Figure 1 by depicting how the strategising roles of the middle managers are linked.

The middle managers form part of a directorate that needs to align to the strategy of the focal government department as depicted in the high-level planning documents. When the high-level strategy of the department is shared with the middle manager, they have to make sense of the strategy and convince the officials who report to them to implement the strategy. As shown in Figure 2, the strategy must be broken down into deliverables or activities that are implementable by all staff members. The activities that are instrumental in bringing success to the government strategy fall in the ambits of their implementation role. The strategy will need to be monitored and evaluated in order to gauge if the deliverables or activities are moving in the direction of achieving the mandate of the government for the 5-year electoral cycle. The 5-year electoral cycle should feed into the NDP deliverables per department. The monitoring and evaluation role of the middle manager is particularly important as it enables the middle manager to provide 
valuable feedback to the government department which could potentially assist in the planning of future strategic documents.

\section{Recommendations}

As this research was limited to one government department, the study findings cannot be generalised to other settings. Despite the limitations, we believe that our research findings offer substantial evidence suggesting that middle managers should be more involved in the crafting of the high-level strategies of the selected government department. The results showed that the middle managers act as a buffer between the top-level and lower level staff in the implementation of the strategy, and operate predominantly at a functional and operational level. It is suggested that their involvement would improve the crafting of the strategy at the selected government department which would aid in the delivery of the strategy within the department. This is because the middle manager occupies multiple roles and needs the support of senior management to bring about the required change (Hansell 2018:231). The middle managers are at the operational level of the strategy and with their experience of dealing with the strategy hands-on, they can provide valuable insights in terms of how activities can be changed or adjusted to ensure the success of the implementation of the strategy. The middle managers are therefore in a direct position to affect the success of the strategy.

In this study, the middle managers used workshops and meetings to monitor and report on strategy implementation and more of these sessions are recommended - but in a less formal manner. Informal networks allow for improved communication across departments and sections, and may alert stakeholders about their non-compliance or nonadherence to policy. In addition, some of the middle managers confirmed that these tools could also be utilised in the crafting of the government strategy. The use of the strategy tools provides invaluable insight into how the department can improve on its strategy implementation through more informal networks.

Furthermore, with the use of the strategy tools, specific communication strategies that enable micro-level discussions are recommended. We believe that this micro-level dialogue enables the nitty-gritty activities that involve strategy work. When strategy is discussed at this level, senior management can gauge if the officials understand the strategy of the department, and how they can promote the achievement of the strategy. The senior managers can get a perspective from the real implementers of the strategy on how they can improve the strategising process.

We recommend further research on how middle management participation in crafting high-level strategies can be enhanced. We also recommend further research on which of the tools enable strategy implementation and what constrains the strategising work of the middle manager. What could also be of interest is to determine how middle managers themselves facilitate or delay strategising.

\section{Conclusion}

We responded to the call for more research in the public sector and the middle management perspective by investigating and identifying the strategising roles of middle managers in the public sector. By using the strategy-as-practice perspective, we were able to identify three key roles as well as the practices that enabled them to carry out these roles successfully.

Most of the middle managers did not have much involvement in the crafting of the high-level strategy, although they played a fundamental role in implementing the strategy. One of the key findings showed that middle managers were eager for more engagement in the crafting of strategic priorities, rather than just the implementation of these issues, as they felt that they were in a position to positively affect the crafting of strategies. The middle managers felt a sense of responsibility as they were key in the alignment of the strategy both vertically and horizontally. Therefore, they had valuable insights into the challenges and barriers experienced on a daily basis which could affect how strategies are developed and implemented in the future. The middle managers are in an ideal position to share the nitty-gritty practices that take place on a daily basis that affect strategy.

The strategising roles of the middle manager proved to be complex and diverse, and were grouped according to three key roles: sense-making and sense-giving, implementation, and monitoring and evaluation. The roles that were discussed were similar to those of the middle managers within the private sector as carried out in studies by Balogun and Rouleau (2011:972) and Salih and Doll (2013:35). The roles are similar in that the middle managers have been identified as strategic actors, they play a fundamental role in monitoring activities and they have to articulate and convince others to follow the decisions of top management (Jansen van Rensburg et al. 2014; Jooste \& Fourie 2009; Mantere 2008; Peris-Bonet et al. 2010; Salih \& Doll 2013; Wooldridge \& Floyd 1990). The public sector can draw on best practices in similar studies with regard to the middle manager in the private sector to improve the rate of strategy implementation, thereby aligning to the deliberate strategy of government.

Within this research, we observed numerous descriptions of how the middle manager had to make sense of how they understood and interpreted government strategy for themselves and then communicated these strategies to the lower and senior officials within the focal government department. The sense-making and sense-giving role of the middle manager was crucial as it involved the interpretation, translation and communication of the strategy effectively to both the lower level managers and top management. The findings further confirm the view of Pretorius (2014:12) that the middle managers drew on their sense-making in understanding crucial information, encoding new information and understanding one's own cognitive capacity. Depending on how well this role is adopted by the middle manager, it may either delay or facilitate strategyimplementation. In addition, the middle manager had 
to correctly monitor and evaluate the achievement of the government priorities at directorate level, which meant that the middle manager was involved in vertical and horizontal strategy implementation.

We expected confirmation of the middle managers' implementation role, given the deliberate strategies, central control and compliance-driven context of the public sector. However, it was interesting to note that the middle managers not only operationalised the deliberate strategies, but also devised new strategies (emergent) as it became necessary while performing their strategising roles. These emergent strategies were evident during the translation, interpretation and implementation of the strategy and were necessary to ensure the successful implementation of the deliberate strategy. In addition, teamwork and building effective teams were a crucial part of their responsibilities in their implementation role.

Many of the middle managers' activities were linked to the development of emergent strategies, as they were informal and unscripted actions that led to strategy implementation. This meant that middle managers had to use their intuition and ingenuity when forming and relying on these informal networks to carry out important activities. This is an example of how middle managers stepped out of their traditional role to ensure that important tasks were accomplished. An encouraging aspect is that despite the restrictive and bureaucratic structures, teamwork was encouraged and played a crucial role in the functioning of the department. This eliminated the issue of the silo effect that is often common in structures of this nature.

In conclusion, the study brought to the fore the voices of the public sector middle managers with regard to the strategising roles that they undertake to realise these strategies, and has opened up the micro-strategising dialogue within the public organisational context. By identifying the three key roles adopted by the middle managers and identifying the key practices associated with these roles within a public department, the study was able to highlight the vital strategising role that middle managers play within their position.

\section{Acknowledgements}

The manuscript is based on a Master of Commerce in Business Management dissertation entitled 'A case study exploring how middle managers implement deliberate strategy in a government department'. The study involved the student Ms J. Surju who was supervised by Ms Nadine De Metz (supervisor) and Prof. Annmarie Davis (co-supervisor) from the University of South Africa.

\section{Competing interests}

The authors declare that they have no financial or personal relationships that may have inappropriately influenced them in writing this article.

\section{Authors' contributions}

All authors contributed equally towards the writing of the article.

\section{Funding information}

This work was supported by South Africa's Department of Education and Training, University of South Africa.

\section{Data availability statement}

Data sharing is not applicable to this article.

\section{Disclaimer}

The views and opinions expressed in this article are those of the authors and do not necessarily reflect the official policy or position of any affiliated agency of the authors.

\section{References}

Alford, J. \& Greve, C., 2017, 'Strategy in the public and private sectors: Similarities, differences and changes', Journal of Administrative Sciences 7(35), 1-17. https:// doi.org/10.3390/admsci7040035

Amason, A.C., 2011, Strategic management from theory to practice, Taylor \& Francis, New York, NY.

Andrews, R., Boyne, G.A., Law, J. \& Walker, R.M., 2011, 'Strategy implementation and public service performance', Administration \& Society 43(6), 643-671. https://doi. org/10.1177/0095399711412730

Balogun, J. \& Rouleau, L., 2011, 'Middle managers, strategic sensemaking and discursive competence', Journal of Management Studies 48(5), 953-983. https:// doi.org/10.1017/jmo.2014.35

Bertram, C. \& Christiansen, I., 2014, Understanding research: An introduction to reading research, Van Schaik, Pretoria.

Bornman, D.A.J., 2017, 'Investigating the expectations of business management students as future leaders regarding the influence of leadership on organisational study: A survey at a South African tertiary institution', Acta Commerci 17(1), 1-10. study: A survey at a South African tertiar
https://doi.org/10.4102/ac.v17i1.492

Candido, C.J.F. \& Santos, S.P., 2015, 'Strategy implementation: What is the failure rate?', Organisation and Management 21(2), 237-262. https://doi.org/10.1017/ jmo.2014.77

Cardoso, F. \& Lavarda, R., 2011, 'Strategy implementation: Practical activities implementing the deliberate strategy', paper presented at V Encontro de Estudos em Estratégia, Porto Alegre, 15-17th May.

Carpenter, V. \& Jiang, N., 2013, 'A case study of issues of strategy implementation in internationalization of higher education', The International Journal of Educational Management 27(1), 4-18. https://doi.org/10.1108/09513541311289792

Cornelissen, J. \& Schildt, H., 2015, 'Sensemaking in strategy as practice: A phenomenon or a perspective?', in D. Golsorkhi, L. Rouleau, D. Seidl \& E. Vaara (eds.), Cambridge handbook of strategy as practice, 2nd edn., pp. 345-364, Cambridge University Press, Cambridge.

Department of Planning, Monitoring and Evaluation (DPME), 2014, 2014 Medium Term Strategic Framework (MTSF) 2014-2019, Department of Planning, Monitoring and Evaluation, Pretoria.

Döös, M., Johansson, P. \& Wilhelmson, L., 2015, 'Beyond being present: Learningoriented leadership in the daily work of middle managers', Journal of Workplace Learning 27(6), 408-425. https://doi.org/10.1108/JWL-10-2014-0077

Flick, U., 2014, The Sage handbook of qualitative data, Sage, London.

Gilbert, G. \& Sutherland, M., 2013, 'The paradox of managing autonomy and control: An exploratory study', South African Journal of Business Management 44(1), 1-14. https://doi.org/10.4102/sajbm.v44i1.144

Gillham, B., 2008, Case study research methods, British Library Cataloguing in Publication Data, London.

Govender, N.M. \& Pretorius, M., 2015, 'A critical analysis of information and communications technology adoption: The strategy-as-practice perspective', Acto Commerci 15(1), 1-13. https://doi.org/10.4102/ac.v15i1.229

Güney, S. \& Taylor, J.R., 2014, 'Rethinking the role of roadmaps in strategic planning: A close-up analysis from project development in corporate R \& D', Qualitative Research in Organizations and Management: An International Journal 9(4), 308-331. https://doi.org/10.1108/QROM-08-2012-1090

Hansell, V., 2018, 'Identifying the prevalence of influential factors on middle managers' abilities to lead organizational change within the context of community nursing and therapy services', International Journal of Healthcare Management 11(3), 225-232. https://doi.org/10.1080/20479700.2017.1315037 
Horst, S.-O. \& Järventie-Thesleff, R., 2016, 'Finding an emergent way through transformational change: A narrative approach to strategy', Journal of Media transformational change: A narrative approach to strategy', Journal of Media
Business Studies 13(1):3-21. https://doi.org/10.1080/16522354.2015.1123854

Jansen van Rensburg, M., Davis, A. \& Venter, P., 2014, 'Making strategy work: The role of the middle manager', Journal of Management and Organization 20(2), 165-186. https://doi.org/10.1017/jmo.2014.33

Jarzabkowski, P. \& Whittington, R., 2008, 'A strategy-as-practice approach to strategy research and education', Journal of Management Inquiry 17(4), 282-286. https:// doi.org/10.1177/1056492608318150

Jones, S. \& Hoop, T., 2017, 'New Zealand's ICT strategy: The respective roles of senio and middle management in promoting collaboration and innovation', Asia and the Pacific Policy Studies 4(3), 484-495. https://doi.org/10.1002/app5.199

Jooste, C. \& Fourie, B., 2009, 'The role of strategic leadership in effective strategy implementation: Perceptions of South African strategic leaders', Southern African Business Review 13(3), 51-68.

Joshi, M. \& Jha, S., 2017, 'Choice of an authoritative style when implementing a survival urgency-based strategic change: A middle manager's perspective', Journal of Strateg and Management 10(2), 168-186. https://doi.org/10.1108/JSMA-06-2014-0041

Katoma, F.N. \& Ungerer, M., 2011, 'The role of middle managers in strategy execution: A case study of a local authority council in Namibia', Journal of Politeia 30(3), 31-53.

Lê, J.K., Seidl, D. \& Suddaby, R., 2013, 'Strategy-as-practice meets neo-institutiona theory', Journal of Strategic Organization 11(3), 329-344. https://doi. org/10.1177/1476127013497618

Livijn, M., 2019, 'Navigating in a hierarchy: How middle managers adapt macro design', Journal of Organization Design 8(7), 1-27. https://doi.org/10.1186/ s41469-019-0046-9

Lystbæk, C.T., Holmgren, J. \& Friis, O.U., 2017, 'Strategy discourses in public sector organizations: A qualitative focus group study', International Public Management Review 18(1), 21-44

Mantere, S., 2008, 'Role expectations and middle manager strategic agency', Journa of Management Studies 45(2), 294-316.

Marin, J., 2012, 'The impact of strategic planning and the balanced scoreboard methodology on middle managers' performance in the public sector', International Journal of Business and Social Sciences 3(1), 114-127.

Mayne, J. \& Zapico-Goni, E., 2017, Monitoring performance in the public sector, Routledge, New York, NY.

Mintzberg, H. \& Waters, J.A., 1985, 'Of strategies, deliberate and emergent', Strategic Management Journal 6(3), 257-272. https://doi.org/10.1002/smj.4250060306

National Planning Commission (NPC), 2013, National Development Plan 2030: Ou future - Make it work, The Presidency, Pretoria.

National Treasury, 2010, Framework for strategic plans and annual performance plan, National Treasury, Pretoria.

National Treasury, 2019, 2019 budget review, National Treasury, Pretoria.

Nonaka, I., 1988, 'Toward middle-up-down management: Accelerating information creation', Sloan Management Review 29(3), 9-18.

Olsson, O.V., Aronsson, H. \& Sandberg, E., 2017, 'Middle management involvement in handling variable patient flows', Management Research Review 40(9), 1007-1024. https://doi.org/10.1108/MRR-05-2016-0114

Orlikowski, W.J., 2015, 'Practice in research: Phenomenon, perspective and philosophy', in D. Golsorkhi, L. Rouleau, D. Seidl \& E. Vaara (eds.). Cambridge handbook of strategy as practice, 2nd edn., pp. 33-35, Cambridge University Press, Cambridge.
O'Shannassy, T., 2009, 'Investigating the role of middle managers in strategy-makingprocess: An Australian method study' International Journal of Management and Organization 20(2), 187-205. https://doi.org/10.1017/jmo.2014.29

Peris-Bonet, F., Canet-Giner, M.T. \& Lavarda, R., 2010, 'How middle managers contribute to strategy formation process: Connection of strategy processes and strategy practices', Revista de Administração de Empresas 50(4), 358-370. https:// doi.org/10.1590/S0034-75902010000400002

Pretorius, M., 2014, 'A competency framework for business rescue practitioner framework', Acta Commerci 14(2), 1-15. https://doi.org/10.4102/ac.v14i2.227

Ridder, H., Hoon, C. \& McCandless, A., 2015, 'The theoretical contribution of case study research to the field of strategy and management', Research Methodology in Strategy and Management 5, 137-175. https://doi.org/10.1108/S14798387(2009)0000005007

Rouleau, L., Balogun, J. \& Floyd, S.W., 2015, 'Strategy-as-practice research on middle managers' strategy work', in D. Golsorkhi, L. Rouleau, D. Seidl \& E. Vaara (eds.) Cambridge handbook of strategy as practice, 2nd edn., pp. 598-615, Cambridge University Press, Cambridge.

Saldaña, J., 2009, The coding manual for qualitative researchers, Sage, London.

Salih, A. \& Doll, Y., 2013, 'A middle management perspective on strategy implementation', International Journal of Business and Management 8(22), 32-39. https://doi.org/10.5539/ijbm.v8n22p32

Samra-Fredericks, D., 2003, 'Strategising as lived experience and strategists' everyday efforts to shape strategic direction', Journal of Management Studies 40(1), 141-174. https://doi.org/10.1111/1467-6486.t01-1-00007

Sloan, J., 2014, Learning to think strategically, 2nd edn., Routledge, New York, NY.

Spee A.P. \& Jarzabkowski, P., 2009, 'Strategy tools as boundary objects', Journal of Strategic Organization 7(2), 223-232. https://doi.org/10.1177/1476127009102674

Stander, K. \& Pretorius, M., 2016, 'The next step in the strategy-as-practice evolution: A comparative typology matrix', Acta Commercii 16(1), 1-11. https://doi. org/10.4102/ac.v16i1.328

Sting, F.J. \& Loch, C.H., 2016, 'Implementing operations strategy: How vertical and horizontal coordination interact', Production and Operations Management 25(7), 1177-1193. https://doi.org/10.1111/poms.12537/abstract

The Presidency, 2014, Twenty year review: South Africa 1994-2014, The Presidency, Pretoria.

Thompson, J. \& Martin, F., 2010, Strategic management awareness and change, Cengage Learning EMEA, Hampshire.

Vaara, E. \& Whittington, R., 2012, 'Strategy-as-practice: Taking social practices seriously', Journal of Academy of Management 6(1), 285-336. https://doi.org/10 $.5465 / 19416520.2012 .672039$

Van Niekerk, A. \& May, M., 2012, 'Exploring how middle managers experience the impact of senior management on their integrity', South African Journal of Labour Relations 36(2), 42-61.

Veldman, J. \& Szabo, A., 2015, Strategy for the public and private sector: How to write a strategic plan, Van Gorcum Publishers.

Wooldridge, B. \& Floyd, S.W., 1990, 'The strategy process, middle management, and organisational performance', Strategic Management Journal 11(3), 231-241. https://doi.org/10.1002/smj.4250110305

Yin, R.K., 2009, Case study research: Design and methods, 4th edn., Sage, Los Angeles, CA.

Yin, R.K., 2011, Qualitative research from start to finish, Guilford Press, New York, NY. 